\title{
CORRELATES AND OUTCOMES OF ALCOHOL USE AFTER SINGLE SOLID ORGAN TRANSPLANTATION: \\ A SYSTEMATIC REVIEW AND META-ANALYSIS
}

\begin{abstract}
Background: Reviews on alcohol use in transplant recipients focus on liver recipients and their risk of post-transplant rejection, but do not assess alcohol use in kidney, heart, or lung transplant recipients. This systematic review and meta-analysis aims to synthesize the evidence on correlates and outcomes of any alcohol use and at-risk drinking after solid organ transplantation (Tx).
\end{abstract}

Methods: $\quad$ We searched 4 databases for quantitative studies in adult heart, liver, kidney and lung Tx recipients, investigating associations between post-Tx alcohol use and correlates and/or clinical, economic or quality of life outcomes. Paper selection, data extraction and quality assessment were performed by 2 reviewers independently. A pooled odds ratio (OR) was computed for each correlate/outcome reported $\geq$ 5 times.

Results: Of the 5,331 studies identified, 76 were included in this systematic review $(93.3 \%$ on liver Tx; mean sample size 148.9 (SD=160.2); $71.9 \%$ male; mean age 48.9 years ( $\mathrm{SD}=6.5$ ); mean time post-Tx 57.7 months $(S D=23.1))$. On average, $23.6 \%$ of patients studied used alcohol post-transplant. Ninety-three correlates of any post-Tx alcohol use were identified, and 9 of the 19 pooled ORs were significantly associated with a higher odds for any post-Tx alcohol use: male gender, being employed post-transplant, smoking pre-transplant, smoking post-transplant, a history of illicit drug use, having first-degree relatives who have alcohol-related problems, sobriety $<6$ months prior to transplant, a history of psychiatric illness, and having received treatment for alcohol-related problems pre-transplant. On average $15.1 \%$ of patients had at-risk drinking. A pooled OR was calculated for 6 of the 47 correlates of post-Tx at risk drinking investigated, of which pre-transplant smoking was the only correlate being significantly associated with 
this behavior. None of the outcomes investigated were significantly associated with any use or at-risk drinking.

Conclusion: Correlates of alcohol use remain under-investigated in solid organ transplant recipients other than liver transplantation. Further research is needed to determine whether any alcohol use or atrisk drinking is associated with poorer post-transplant outcomes. Our meta-analysis highlights avenues for future research of higher methodological quality and improved clinical care.

\section{KEY WORDS}

Alcohol use, solid organ transplantation, systematic review, meta-analysis, risk factors, post-transplant outcome 


\section{INTRODUCTION}

Alcohol consumption is an integral part of many cultures and a common feature of social gatherings. Worldwide, $47.7 \%$ of men and $28.9 \%$ of women drink alcohol, with an average intake of pure alcohol per day of 30-57 grams for men and 10-29 grams for women [1]. While light to moderate intake (i.e., $\leq 2$

Field Coc alcohol units per day for men (28 grams) and maximally 1 unit per day for women (14 grams)) does not increase the risk of mortality or morbidity [2-5], the harmful impact of excessive alcohol use on a person's health cannot be ignored. In 2012, 5.9\% of all global deaths were attributable to alcohol consumption [1]. Problematic alcohol use is the third most common risk factor for global disease burden, representing 5.5\% of global disability-adjusted life years [6] and is a key risk factor in the onset of over 200 diseases and injuries, including cardiovascular disease, cancer, gastrointestinal disorders, diabetes and infectious diseases [7]. The annual economic cost attributable to excessive alcohol use is estimated at $\$ 125$ billion Euros in Europe, and $\$ 224$ billion dollars or about $\$ 1.9$ dollars per alcoholic drink in the United States, corresponding to $1-3 \%$ of a country's gross domestic product globally $[1,8]$.

Within the field of transplantation, alcohol-related research almost exclusively concentrates on alcoholic cirrhosis as an etiology of end-stage liver disease, and the prevalence and, to a lesser extent, predictors of relapse after liver transplantation [9]. Currently, about 1 out of 3 liver transplantations are performed for alcoholic liver disease [10]. Post-transplant survival and quality of life (QOL) are similar for patients undergoing transplantation for alcoholic liver cirrhosis versus for other etiologies. Some studies even suggesting a lower rejection rate and graft loss from rejection in those transplanted for alcoholic liver disease versus other indications [11]. Yet, in the case of alcohol relapse, occurring in an estimated 5.6 cases per 100 per year [12], long-term survival is poorer due to the increased risk for cardiovascular disease and cancer in those consuming alcohol post-transplant. Few studies have investigated the prevalence and clinical consequences of alcohol use in kidney, lung or heart transplant patients, with percentages between
Field Coc

Field Coc

Field Coc

Field Coc

Field Coc

Field Coc

Field Coc

Field Coc

Field Coc

Field Coc 
0 and $78.2 \%$ being reported post-transplant in a recent narrative review [11]. Varying operational definitions of alcohol use, measurement and case finding methods might contribute to this large range in percentages observed. Also, risk factors for post-transplant (excessive) alcohol use have been investigated almost exclusively in liver transplant populations, and predominantly in patients with alcoholic cirrhosis as disease etiology, showing that more severe alcohol use and a shorter duration of abstinence prior to transplantation are associated with a higher risk of post-transplant relapse [13-15]. However, most studies did not use a theoretical framework underpinning the selection of variables under investigation, and without effect sizes being calculated, it is difficult to appreciate a correlate's true relationship with posttransplant drinking behavior and its subsequent association with outcome. To our knowledge, no systematic reviews have ever investigated a broad spectrum of correlates and outcomes, using a metaanalytic approach among all solid organ transplant populations, in patients abstaining from alcohol use, drinking at moderate levels, or showing at-risk drinking patterns (i.e., not only focusing on liver transplantation or a single organ type).

The aims of this systematic review and meta-analysis were to: 1 ) investigate the correlates of posttransplant alcohol use in adult heart, liver, kidney and lung transplant recipients, and 2) quantify the clinical, economic and health-related quality of life outcomes of post-transplant alcohol use in solid organ transplant recipients. 


\section{MATERIALS AND METHODS}

This systematic review and meta-analysis is one of four systematic reviews conducted, investigating the relationships between correlates or outcomes and alcohol use, immunosuppressant medication nonadherence, smoking [16], or physical inactivity following transplantation through the Brocher funded

grant to develop a Solid organ transplant Endpoint model on Relationships between Influencing factors and Outcomes of transplant Self-Management behaviors Consortium.

We designed a systematic review protocol based on the methodology outlined in the Center for Reviews and Dissemination handbook [17] and followed the PRISMA guidelines for data reporting [18]. The protocol is registered in the PROSPERO database (REGISTRATION NUMBER REMOVED IN ORDER NOT TO REVEAL THE AUTHORS4 IDENTITY)[19].

Field Coc Field Coc

Field Coc

\section{Electronic database searches}

The electronic databases of PubMed, Embase.com, PsycINFO (Ovid), and CINAHL (Ebscohost) were searched from inception until April 30, 2016. The search string was first designed for PubMed in close collaboration with a health sciences librarian (MLK), combining controlled vocabulary (MESH terms) and free text words representing the concepts of alcohol consumption and solid organ transplantation (Table 1), and translated afterwards for the other databases (available from the researchers upon request). The bibliographic software program EndNote ${ }^{\circledR}$ was used to manage the references emerging from the comprehensive electronic database searches.

\section{INSERT TABLE 1 ABOUT HERE}

Titles and abstracts of references were screened against inclusion- and exclusion criteria by two reviewers independently. Next, the full texts of all potentially relevant references were retrieved and assessed for eligibility by two independent reviewers. Evaluations were compared and inconsistencies resolved via 
consensus or consultation with a third reviewer. Eligibility scores were documented using checklists programmed in a Microsoft Access database for transparency. The reference list of eligible studies was subsequently screened for additional studies meeting the pre-specified inclusion criteria. For companion or duplicate papers, only the most recent publication was considered. If similar or follow-up results were reported in different papers (i.e. companion papers), we included the paper with the largest sample size or most complete dataset only.

\section{Inclusion and exclusion criteria}

Studies eligible for inclusion in this systematic review had to fulfill the following criteria: 1) report on original or primary quantitative studies; 2 ) include adult ( $>18$ years of age) recipients of single heart, liver, kidney or lung transplants; 3 ) address alcohol use; and 4) focus either on the association between posttransplant alcohol use and clinical, economic or health-related quality of life outcomes, or on correlates of post-transplant alcohol use, or both.

The following papers were excluded: 1) publications that did not report results from an original quantitative research project (e.g. qualitative studies, case reports with single subjects, reviews, books, consensus reports, statements, editorials, letters to the editor, or dissertations); 2) studies on combined organ transplant populations (e.g. liver and kidney), or other forms of tissue or organ transplantation (e.g. stem cell or pancreas transplantation); 3) studies focusing on children or adolescents $<18$ years of age; and 4) quantitative studies focusing on a different topic or not addressing correlates or outcomes of posttransplant alcohol use. Studies were also excluded if they had insufficient information to allow effect size calculation based on the results published or full texts that could not be found.

\section{Data extraction}

A codebook was designed and programmed in an Access 2007 database (Microsoft, Seattle, WA, USA) to guide the data extraction, covering the following sections: a) general information on the paper (e.g., year 
of publication, country of origin, funding source of study, organ type); b) study methods (e.g. study design, sample size and characteristics (e.g. age, gender, time since transplant); c) theoretical framework underpinning the investigation of correlates or outcomes of alcohol use; d) clinical, economic and healthrelated quality of life outcomes; e) correlates; f) quality assessment criteria; and g) specific information regarding prevalence and measurement methods documenting post-transplant alcohol use.

The correlates were further divided into social/economic-related, patient-related, condition-related, treatment-related and healthcare team or system related correlates, in line with the taxonomy used by the World Health Organization to classify correlates of medication adherence [20], and to facilitate comparisons of results between the parallel systematic reviews on post-transplant smoking behavior, physical inactivity and medication nonadherence. Clinical, economic and health-related quality of life outcomes represent conditions that are not yet present at time of transplantation but occur during the post-transplant trajectory. If conditions (e.g. diabetes mellitus) were present prior to or at time of transplantation, they were classified as condition-related correlates.

We distinguished between studies reporting any alcohol use versus at-risk drinking (i.e., drinking alcohol in amounts that could cause adverse health effects; defined as drinking $>2$ units per day for men and $>1$ unit per day for women) [2], and correlates and outcomes were extracted accordingly.

Both the codebook and taxonomy on correlates and outcomes were developed iteratively, piloted and adapted until there was $100 \%$ consensus among the consortium partners.

Data extraction was again performed by two researchers independently, and inconsistencies resolved until there was $100 \%$ agreement on the data extracted. 


\section{Quality of reporting}

Quality assessment was performed by two reviewers independently using an adapted version of previously published quality evaluation checklists $[21,22]$. The quality of each study was rated in terms of definitions provided, sampling strategies, sample sizes, methodological strength, completeness of data reporting and reproducibility. Each of the 14 quality criteria are reported separately and no total score was calculated, as not all criteria were applicable to all studies.

\section{Data analysis and synthesis}

Study characteristics were summarized by descriptive statistics as appropriate (i.e., percentages, median, or mean depending on the measurement level and distribution of the data). An effect size, expressed as odds ratio (OR) with 95\% confidence interval, was calculated for each correlate or outcome of any alcohol use or at-risk drinking investigated by at least five independent studies. An online effect size calculator was used to facilitate the computation of effect size types per publication (i.e. standardized mean difference, correlation coefficient, odds ratio and risk ratio, depending on the input data available) [23]. All effect size types were subsequently transformed into odds ratios, after which a pooled OR was calculated under a random-effects model across all contributing studies using SAS ${ }^{\circledR}$ [24]. Effect sizes were calculated by two researchers independently and compared afterwards. For each statistically significant pooled $\mathrm{OR}$, the fail-safe $\mathrm{N}$ was calculated to evaluate the impact of publication bias (i.e., studies with statistically significant findings were more likely to be published) [25]. The fail-safe $\mathrm{N}$ represents the number of non-significant studies that would need to be added so that the pooled OR would no longer be statistically significant. The Q-test documenting heterogeneity (i.e. variability in effects among pooled studies), as well as the $\mathrm{I}^{2}$ statistic with $95 \%$ confidence interval to describe the percentage of variation 
across studies that is due to heterogeneity rather than chance were also reported, as these statistics are suitable to describe heterogeneity across small sample studies [26]. If a correlate or outcome was assessed less than 5 times, an overview was produced, indicating the number of publications that showed a significant association with any post-transplant alcohol use or at-risk drinking.

\section{RESULTS}

\section{Sample size}

After title and abstract screening, 513 of 5331 references were eligible for full text analysis. Excluding 4 companion papers, 2 duplicate publications and 431 papers that did not fulfill the inclusion criteria, data on correlates and outcomes from 76 studies were extracted and summarized (Figure 1) [27-102].

\section{INSERT FIGURE 1 ABOUT HERE}

\section{Study characteristics}

Given that 2 publications enrolled the same cohort of patients, but reported different findings [90, 91], study characteristics and quality appraisal was reported for 75 unique studies only.

Except for 4 studies on kidney [32, 37, 56, 101] and 1 study on lung transplant recipients [55], all studies examined correlates and outcomes of alcohol use in liver transplant populations (93.3\%). About half of the studies were conducted in Europe (48\%), followed by 33 studies from North America (44\%), with only 5 studies coming from Asia (6.7\%) and 1 from Australia (1.3\%). The sample size across the 75 studies ranged from 6 to 834 ( mean=148.9; SD=160.2), the average patient age was 48.9 years ( $S D=6.5$ ) (reported in 62 studies only), and a mean of $71.9 \%$ male patients $(S D=15.6)$ (reported in 65 studies) were included. At study enrollment, patients were on average 57.7 months post-Tx ( $S D=23.1$; range 21 to 108 months, reported in 39 studies only). Irrespective of the operational definition of alcohol use used, the mean percentage of patients consuming alcohol post-transplant was estimated at $23.6 \%$ (SD=11.7; range $2.6 \%$ - 
$52.8 \%$; mean weighted for sample size $22.4 \%$ ). At-risk drinking was estimated to occur in $15.1 \%$ of the patients ( $S D=7.1$; range 1.4-28\%; mean weighted for sample size $13.5 \%$ ).

\section{Quality assessment}

Figure 2 illustrates the methodological quality of included studies. Although most studies described how they assessed alcohol use and at what time, they had methodological shortcomings in terms of: unclear definitions of correlates or outcomes, insufficient reporting of the psychometric properties of the instruments used to measure them, inappropriate sample sizes for the number of factors studied, incomplete description of the statistical analysis plan, and lack of a prospective design.

\section{INSERT FIGURE 2 ABOUT HERE}

\section{Correlates of alcohol use}

In total, 93 different correlates were investigated in relation to any post-transplant alcohol use, of which 36 were patient-related, 27 condition related, 17 social-/economic-related, 11 treatment-related and only 2 health-care team /system-related factors (Tables 2 and 3). Pooled effect sizes could be calculated for 19 correlates, of which 9 were significantly positively associated with any alcohol use post-transplant (Table 2), i.e. male gender, being employed post-transplant, smoking pre-transplant, smoking post-transplant, a history of illicit drug use, having first-degree relatives who have alcohol-related problems, sobriety of less than 6 months prior to transplant, a history of psychiatric illness, and having received treatment for alcohol-related problems pre-transplant.

\section{INSERT TABLE 2 ABOUT HERE}

Forty-seven correlates were investigated in relation to at-risk drinking, i.e. 14 condition-related, 13 patient-related, 11 social- /economic-related, 7 treatment-related correlates, and 2 factors related to the healthcare team or system (Table 2 and 3). A pooled effect size could be calculated for 6 correlates, of 
which pre-transplant smoking was the only one being significantly associated with post-transplant at-risk drinking (Table 2).

Correlates of any alcohol use and at-risk drinking for which no pooled effect sizes could be calculated, are presented in Table 3.

\section{INSERT TABLE 3 ABOUT HERE}

\section{Outcomes of alcohol use}

Twenty-three outcomes were studied in relation to any alcohol use. None of the 3 outcomes for which a pooled effect size could be calculated was significantly associated with any post-transplant alcohol use (Table 2).

\section{INSERT TABLE 4 ABOUT HERE}

Similarly, out of 17 outcomes studied in relation to at-risk drinking, a pooled effect size could be calculated for one outcome, yet mortality was not significantly associated with post-transplant at-risk drinking. Outcomes for which no pooled effect size could be calculated are presented in Table 3. 


\section{DISCUSSION}

To the best of our knowledge, this is the first systematic review and meta-analysis that simultaneously assessed correlates and outcomes of post-transplant alcohol use in different single adult solid organ transplant populations. We had several key findings that are of importance for both research and clinical practice.

First, studies focused almost exclusively on correlates and outcomes of post-transplant alcohol use in liver transplant recipients. We could only include five studies on kidney or lung transplant patients, of which two did not had alcohol use as their prime focus $[32,37]$. This is not surprising, as alcoholic cirrhosis is among the leading indications for liver transplantation, and transplant teams remain concerned about the risk of alcohol use relapse. However, given that drinking alcohol is a common practice in the general population and that excessive alcohol use is the third most common risk factor for global disease burden [6], the lack of evidence on correlates of alcohol use and their impact on post-transplant outcome in other transplant populations is unexpected. A cross-sectional study revealed that about $9 \%$ of patients on the wait list for heart or lung transplantation drank above safety levels[103], a behavior that most likely will continue without follow-up. It remains to be investigated whether alcohol use, be it any use or at-risk drinking will affect graft outcomes in solid organ transplant groups other than liver transplantation. Several studies in our meta-analysis reported alcohol use and even at-risk drinking in patients undergoing liver transplantation for other indications, highlighting that regular assessment of alcohol use should be part of routine follow-up of all transplant patients both pre- and post-transplant, and irrespective of disease etiology. Self-report is still the prevailing assessment method, yet, specific attention should be given to maximize accuracy of alcohol use measures [104], in particular in populations without a known history of alcohol-related problems, as drinking patterns might be more benign and hence remain more hidden. Although this was not the purpose of the present review, our pooled prevalence of any alcohol use (23.6\%) 
and at-risk drinking (15.1\%) are consistent with prevalence rates previously documented in liver transplantation $[14,15]$.

Second, our study is the first to disentangle any post-transplant alcohol use from at-risk drinking. A large number of correlates have been explored in relation to any alcohol use (i.e. 93 correlates), yet for only 19 (20.2\%) a pooled effect size could be calculated, of which 9 factors showed a significant association with post-transplant alcohol use. Our results coincide with previous studies that focused on psychiatric risk profiles of pre-Tx alcohol use [105], showing that patients with mental health problems and patients with other addiction problems (smoking, illicit drug) require close monitoring and appropriate supportive interventions. Pre-Tx treatment might indicate more severe alcohol use. It remains unclear, however, whether patients attending pre-transplant treatment programs were successful in giving up alcohol use completely prior to transplant or whether supportive interventions were sustained post-transplant. These are two alternative hypotheses why a relationship between having received treatment pre-transplant and post-transplant alcohol use is observed. Although our findings and those of previous reviews demonstrate the relevance of the 6-months abstinence rule prior to (liver) transplant $[12,13]$, a debate is ongoing within the literature on whether this rule should be abandoned for patients with a poor survival prognosis on the waiting list [106]. Rather than debating the pre-transplant length of sobriety, our efforts should shift towards pre-transplant screening programs and support programs, not only for people with alcoholic liver disease, but also for all transplant candidates. If starting treatment already prior to Tx is not possible (e.g. because of the medical condition of the patient or the urgency of the Tx), professionals should make every effort to provide appropriate and sustainable support after Tx. Although successful alcohol treatment programs exist [107], they unfortunately have not yet been formally tested in pre- and post-transplant populations. In addition, our finding that patients returning to work are more prone to alcohol use or relapse post-transplant is intriguing, yet, it remains unclear whether this also results in poor outcomes. Epidemiologic studies outside the field of transplantation suggest that working post-transplant might 
induce higher stress, which might trigger alcohol use as a stress reliever_[108][105], a hypothesis that merits further investigation in transplant populations also.

Third, although most correlates investigated in relation with at-risk drinking and for any alcohol use were similar, only pre-transplant smoking was significantly associated with at-risk drinking post-Tx. This is surprising, given that most Tx centers nowadays urge patients to give up smoking prior to listing. On the other hand, similar to excessive alcohol use, smoking is an addiction, explaining why smoking and alcohol use might often go hand in hand. Alcoholic cirrhosis as an etiology of end-stage liver disease was not a significant predictor, which is surprising, as previous reviews often leave the impression that this population is particularly at-risk for relapse and/or problematic drinking post-transplant [13-15]. Not all studies clearly define alcohol use. Future studies should pay close attention to the operational definition, alongside using a valid assessment method to detect alcohol use, and investigate risk factors for different degrees of alcohol use severity. A more comprehensive approach in assessing risk factors is also needed, as most studies a) examine single or few correlates simultaneously, b) tend to focus on factors that cannot be changed (e.g. condition-related or demographic factors), c) did not use theoretical models to guide that selection of relevant drivers of the behavior under study, and d) ignore that factors related to the healthcare provider and healthcare setting might play perhaps a bigger role than patient-level factors.

Fourth, in contrast to most reviews focusing on correlates exclusively, we also examined outcomes. The current state-of-the-art evidence does not indicate that any drinking alcohol post-transplant places transplant patients at a higher risk for poorer post-transplant outcomes. This is surprising, giving that multiple studies describe the detrimental impact of alcohol use on mortality and morbidity, yet perhaps this might only be true for harmful drinking patterns. Unfortunately, we could not calculate a pooled effect size for most of the outcomes investigated, hence this conclusion should await of future studies that clearly distinguish between mild and severe alcohol use and take time since transplantation into consideration. 
Our study had some limitations. First, our review might have missed potentially relevant studies, although the chances are low, given the systematic approach we used to screen the available literature, including checking the reference lists of retrieved studies. Second, no specific taxonomy currently exists to classify alcohol-use specific correlates. However, we classified correlates using the World Health Organization taxonomy for medication adherence correlates [20], and our taxonomy allows for comparison of risk factors for other health behaviors, including medication adherence, smoking and physical activity, that are currently investigated in 3 systematic reviews conducted in parallel with ours. Moreover, by classifying risk factors, one is able to immediately see opportunities for new research, as healthcare system related factors, for instance, have not been investigated in great detail in relation to post-transplant alcohol use. Third, for most correlates and outcomes, substantial heterogeneity can be noted (for which we used a random-effects pooling technique). Fourth the fail-safe $\mathrm{N}$ is often small, hence our results should be interpreted with caution as it is possible that there is publication bias in that studies with significant findings are more likely to be published. Finally, although many studies suffer from methodological shortcomings, we did not stratify our findings based on study quality. Rather, we use these insights as recommendations for future studies, including the need for prospective research with sufficiently large sample sizes that clearly describe their sample, appropriately define alcohol use, and use reliable and valid measurement methods for assessing correlates and/or outcomes.

In conclusion, our systematic review is highly innovative as it is the first to assess both correlates and outcomes of post-transplant alcohol use not only in liver transplantation, but also in kidney, heart and lung transplantation. Our meta-analytic approach illuminates important avenues for further research and improvement of clinical care. 


\section{REFERENCES}

\section{REFERENCES}

1. World Health Organisation. Global Status report on Alcohol and Health 2014. available from: http://apps.who.int/iris/bitstream/handle/10665/112736/9789240692763_eng.pdf;jsessionid=B CAD94FAE55A65A25C3F12097608FB1D?sequence $=1$ (accessed on March 7, 2018)

2. National Institute of Alcohol Abuse and Alcoholism: Drinking Levels defined: Available from: http://www.niaaa.nih.gov/alcohol-health/overview-alcohol-consumption/moderate-bingedrinking. (accessed on January 2, 2018)

3. Wood AM, Kaptoge S, Butterworth AS, Willeit P, Warnakula S, Bolton T,et al. Risk thresholds for alcohol consumption: combined analysis of individual-participant data for 599912 current drinkers in 83 prospective studies. Lancet 2018;391(10129): 1513-1523.4. Roerecke M, Rehm J. Alcohol intake revisited: risks and benefits. Curr Atheroscler Rep 2012;14(6):556-62. doi: 10.1007/s11883-012-0277-5.

5. O'Keefe JH, Bhatti SK, Bajwa A, DiNicolantonio JJ, Lavie CJ. Alcohol and cardiovascular health: the dose makes the poison...or the remedy. Mayo Clin Proc 2014;89(3):382-93. doi: 10.1016/j.mayocp.2013.11.005.

6. Lim SS, Vos T, Flaxman AD, Danaei G, Shibuya K, Adair-Rohani H, et al. A comparative risk assessment of burden of disease and injury attributable to 67 risk factors and risk factor clusters in 21 regions, 1990-2010: a systematic analysis for the Global Burden of Disease Study 2010. Lancet 2012;380(9859):2224-60. doi: 10.1016/S0140-6736(12)61766-8.

7. Shield KD, Parry C, Rehm J. Chronic diseases and conditions related to alcohol use. Alcohol Res 2013;35(2):155-73.

8. Rehm J, Mathers C, Popova S, Thavorncharoensap M, Teerawattananon Y, Patra J. Global burden of disease and injury and economic cost attributable to alcohol use and alcohol-use disorders. Lancet 2009;373(9682):2223-33. doi: 10.1016/S0140-6736(09)60746-7.

9. Marot A, Dubois M, Trépo E, Moreno C, Deltenre P. Liver transplantation for alcoholic hepatitis: A systematic review with meta-analysis. PLoS One 2018; 13(1):e0190823. doi: 10.1371/journal.pone.0190823.

10. Singal AK, Guturu P, Hmoud B, Kuo YF, Salameh H, Wiesner RH. Evolving frequency and outcomes of liver transplantation based on etiology of liver disease. Transplantation 2013;95(5):755-60. doi: 10.1097/TP.0b013e31827afb3a.

11. Parker R, Armstrong MJ, Corbett C, Day EJ, Neuberger JM. Alcohol and substance abuse in solidorgan transplant recipients. Transplantation 2013;96(12):1015-24. doi: 10.1097/TP.0b013e31829f7579.

12. Dew MA, diMartini AF, Steel J, De Vito Dabbs A, Myaskovsky L, Unruh M, et al. Meta-analysis of risk for relapse to substance use after transplantation of the liver or other solid organs. Liver Transpl 2008;14(2):159-72. doi: 10.1002/It.21278.

13. McCallum S, Masterton G. Liver transplantation for alcoholic liver disease: a systematic review of psychosocial selection criteria. Alcohol Alcohol 2006;41(4):358-63.

14. DiMartini A, Crone C, Dew MA. Alcohol and substance use in liver transplant patients. Clin Liver Dis 2011;15(4):727-51. doi: 10.1016/j.cld.2011.08.002.

15. Rustad JK, Stern TA, Prabhakar M, Musselman D. Risk Factors for Alcohol Relapse Following Orthotopic Liver Transplantation: A Systematic Review. Psychosomatics 2015;56(1):21-35. doi: 10.1016/j.psym.2014.09.006. 
16. Duerinckx N, Burkhalter H, Engberg SJ, Kirsch M, Klem ML, Sereika SM, et al. Correlates and Outcomes of Posttransplant Smoking in Solid Organ Transplant Recipients: A Systematic Literature Review and Meta-Analysis. Transplantation 2016;100(11):2252-63.

17. Centre for Reviews and Dissemination. CRD's guidance for undertaking reviews in healthcare. University of York, UK 2009. https://www.york.ac.uk/media/crd/Systematic_Reviews.pdf.

18. Moher D, Liberati A, Tetzlaff J, Altman DG, PRISMA Group. Preferred reporting items for systematic reviews and meta-analyses: the PRISMA statement. BMJ 2009;21(339). doi: 10.1136/bmj.b2535.

19. Briganti DF, D'Ovidio F. Long-term management of patients with end-stage lung diseases. Best Pract Res Clin Anaesthesiol 2017;31(2):167-78. doi: 10.1016/j.bpa.2017.07.007.

20. World Health Organization. Adherence to long-term therapies: evidence for action. World Health Organisation 2003.

http://www.who.int/chp/knowledge/publications/adherence_full_report.pdf?ua=1

21. Härlein J, Dassen T, Halfens RJ, Heinze C. Fall risk factors in older people with dementia or cognitive impairment: a systematic review. J Adv Nurs 2009;65(5):922-33. doi: 10.1111/j.13652648.2008.04950.x.

22. Cho MK, Bero LA. Instruments for assessing the quality of drug studies published in the medical literature. JAMA 1994;272(2):101-4.

23. Bozkurt B, Colvin M, Cook J, Cooper LT, Deswal A, Fonarow GC, et al. Current Diagnostic and Treatment Strategies for Specific Dilated Cardiomyopathies: A Scientific Statement from the American Heart Association. Circulation 2016;134(23):e579-646.

24. Wang MC, Bushman BJ. Integrating results through meta-analytic review using $\mathrm{SAS}^{\circledR}$ software. New York City: Cary, SAS Institute Inc 1999. ISBN\# 978-1-58025-293-5.

25. Rosenberg MS. The file-drawer problem revisited: a general weighted method for calculating failsafe numbers in meta-analysis. Evolution 2005;59(2):464-8.

26. Li SJ, Jiang $\mathrm{H}$, Yang $\mathrm{H}$, Chen W, Peng J, Sun MW, et al. The dilemma of heterogeneity tests in meta-analysis: a challenge from a simulation study. PLoS One 2015;10(5):e0127538. doi: 10.1371/journal.pone.0127538.

27. Abosh D, Rosser B, Kaita K, Bazylewski R, Minuk G. Outcomes following liver transplantation for patients with alcohol- versus nonalcohol-induced liver disease. Can J Gastroenterol 2000;14(10):851-5.

28. Addolorato G, Mirijello A, Leggio L, Ferrulli A, D'Angelo C, Vassallo G, et al. Liver transplantation in alcoholic patients: impact of an alcohol addiction unit within a liver transplant center. Alcohol Clin Exp Res 2013;37(9):1601-8. doi: 10.1111/acer.12117.

29. Aguilera V, Berenguer M, Rubin A, San-Juan F, Rayon JM, Prieto M, et al. Cirrhosis of mixed etiology (hepatitis $C$ virus and alcohol): Posttransplantation outcome-Comparison with hepatitis C virus-related cirrhosis and alcoholic-related cirrhosis. Liver Transpl 2009;15(1):79-87. doi: 10.1002/It.21626.

30. Ahn CS, Hwang S, Kim KH, Moon DB, Ha TY, Song GW, et al. Long-term outcome of living donor liver transplantation for patients with alcoholic liver disease. Transplant Proc 2014;46(3):761-6. doi: 10.1016/j.transproceed.2013.12.032.

31. Andresen-Streichert $\mathrm{H}$, von Rothkirch $\mathrm{G}$, Vettorazzi E, Mueller A, Lohse AW, Frederking $\mathrm{D}$, et al. Determination of Ethyl Glucuronide in Hair for Detection of Alcohol Consumption in Patients After Liver Transplantation. Ther Drug Monit 2015;37(4):539-45. doi: 10.1097/FTD.0000000000000160. 
32. Bechade C, Le Maître B, Lobbedez T, Bouvier N, Hurault de Ligny B, Châtelet V. [PRETAGREF study: Prevalence of tobacco use and factors associated with smoking cessation in kidney transplant recipients]. Nephrol Ther 2016;12(1):48-55. doi: 10.1016/j.nephro.2015.08.001.

33. Bellamy CO, DiMartini AM, Ruppert K, Jain A, Dodson F, Torbenson M, et al. Liver transplantation for alcoholic cirrhosis: long term follow-up and impact of disease recurrence. Transplantation 2001;72(4):619-26.

34. Berlakovich GA, Windhager T, Freundorfer E, Lesch OM, Steininger R, Mühlbacher F. Carbohydrate deficient transferrin for detection of alcohol relapse after orthotopic liver transplantation for alcoholic cirrhosis. Transplantation 1999;67(9):1231-5.

35. Berlakovich GA, Langer F, Freundorfer E, Windhager T, Rockenschaub S, Sporn E, et al. General compliance after liver transplantation for alcoholic cirrhosis. Transpl Int 2000;13(2):129-35.

36. Berlakovich GA, Soliman T, Freundorfer E, Windhager T, Bodingbauer M, Wamser $P$, et al. Pretransplant screening of sobriety with carbohydrate-deficient transferrin in patients suffering from alcoholic cirrhosis. Transpl Int 2004;17(10):617-21.

37. Bernat Garcia J, Morales Suares-Varela M, Vilata JJ, Marquina A, Pallardo L, Crespo J. Risk factors for non-melanoma skin cancer in kidney transplant patients in a Spanish population in the Mediterranean region. Acta Derm Venereol 2013;93(4):422-7. doi: 10.2340/00015555-1525.

38. Biselli M, Gramenzi A, Del Gaudio M, Ravaioli M, Vitale G, Gitto S, et al. Long term follow-up and outcome of liver transplantation for alcoholic liver disease: a single center case-control study. J Clin Gastroenterol 2010;44(1):52-7. doi: 10.1097/MCG.0b013e3181a390a8.

39. Bjornsson E, Olsson J, Rydell A, Freriksson K, Eriksson C, Sjöberg C, et al. Long-term follow-up of patients with alcoholic liver disease after liver transplantation in Sweden: impact of structured management on recidivism. Scand J Gastroenterol 2005;40(2):206-16.

40. Burra P, Mioni D, Cecchetto A, Cillo U, Zanus G, Fagiuoli S, et al. Histological features after liver transplantation in alcoholic cirrhotics. J Hepatol 2001;34(5):716-22.

41. Campbell DA Jr, Magee JC, Punch JD, Merion RM, Turcotte JG, Bromberg JS. One center's experience with liver transplantation: alcohol use relapse over the long-term. Liver Transpl Surg 1998;4(5 Suppl 1):S58-64.

42. Coffman KL, Hoffman A, Sher L, Rojter S, Vierling J, Makowka L. Treatment of the postoperative alcoholic liver transplant recipient with other addictions. Liver Transpl Surg 1997;3(3):322-7.

43. Conjeevaram HS, Hart J, Lissoos TW, Schiano TD, Dasgupta K, Befeler AS, et al. Rapidly progressive liver injury and fatal alcoholic hepatitis occurring after liver transplantation in alcoholic patients. Transplantation 1999;67(12):1562-8.

44. Cuadrado A, Fabrega E, Casafont F, Pons-Romero F. Alcohol recidivism impairs long-term patient survival after orthotopic liver transplantation for alcoholic liver disease. Liver Transpl 2005;11(4):420-6.

45. De Gottardi A, Spahr L, Gelez P, Morard I, Mentha G, Guillaud O, et al. A simple score for predicting alcohol relapse after liver transplantation: results from 387 patients over 15 years. Arch Intern Med 2007;167(11):1183-8.

46. Deruytter E, Van Steenkiste C, Trépo E, Geerts A, Van Vlierberghe H, Berrevoet F, et al. Liver transplantation for alcoholic liver disease: a retrospective analysis of recidivism, survival and risk factors predisposing to alcohol relapse. Acta Gastroenterol Belg 2013;76(3):282-90.

47. De Simone P, De Geest S, Ducci J, Carrai P, Petruccelli S, Baldoni L, et al. Alcohol drinking after liver transplantation is associated with graft injury. Minerva Gastroenterol Dietol 2011;57(4):345-59.

48. DiMartini A, Magill J, Fitzgerald MG, Jain A, Irish W, Khera G, et al. Use of a high-risk alcohol relapse scale in evaluating liver transplant candidates. Alcohol Clin Exp Res 2000;24(8):1198-201. 
49. DiMartini A, Day N, Dew MA, Lane T, Fitzgerald MG, Magill J, et al. Alcohol use following liver transplantation: a comparison of follow-up methods. Psychosomatics 2001;42(1):55-62.

50. Dumortier J, Guillaud O, Adham M, Boucaud C, Delafosse B, Bouffard Y, et al. Negative impact of de novo malignancies rather than alcohol relapse on survival after liver transplantation for alcoholic cirrhosis: a retrospective analysis of 305 patients in a single center. Am J Gastroenterol 2007;102(5):1032-41.

51. Dumortier J, Dharancy S, Cannesson A, Lassailly G, Rolland B, Pruvot FR, et al. Recurrent alcoholic cirrhosis in severe alcoholic relapse after liver transplantation: a frequent and serious complication. Am J Gastroenterol 2015;110(8):1160-6; quiz 1167. doi: 10.1038/ajg.2015.204.

52. Egawa H, Nishimura K, Teramukai S, Yamamoto M, Umeshita K, Furukawa H, et al. Risk factors for alcohol relapse after liver transplantation for alcoholic cirrhosis in Japan. Liver Transpl 2014;20(3):298-310. doi: 10.1002/lt.23797.

53. Ehlers SL, Rodrigue JR, Widows MR, Reed Al, Nelson DR. Tobacco use before and after liver transplantation: a single center survey and implications for clinical practice and research. Liver Transpl 2004;10(3):412-7.

54. Everson G, Bharadhwaj G, House R, Talamantes M, Bilir B, Shrestha R, et al. Long-term follow-up of patients with alcoholic liver disease who underwent hepatic transplantation. Liver Transpl Surg 1997;3(3):263-74.

55. Evon DM, Burker EJ, Sedway JA, Cicale R, Davis K, Egan T. Tobacco and alcohol use in lung transplant candidates and recipients. Clin Transplant 2005;19(2):207-14.

56. Fierz K, Steiger J, Denhaerynck K, Dobbels F, Bock A, De Geest S. Prevalence, severity and correlates of alcohol use in adult renal transplant recipients. Clin Transplant 2006;20(2):171-8.

57. Foster PF, Fabrega F, Karademir S, Sankary HN, Mital D, Williams JW. Prediction of abstinence from ethanol in alcoholic recipients following liver transplantation. Hepatology 1997;25(6):146977.

58. Gayowski T, Singh N, Keyes L, Wannstedt CF, Wagener MM, Vargas H, et al. Late-onset renal failure after liver transplantation: role of posttransplant alcohol use. Transplantation 2000;69(3):383-8.

59. Gedaly R, McHugh PP, Johnston TD, Jeon H, Koch A, Clifford TM, et al. Predictors of relapse to alcohol and illicit drugs after liver transplantation for alcoholic liver disease. Transplantation 2008;86(8):1090-5. doi: 10.1097/TP.0b013e3181872710.

60. Gerhardt TC, Goldstein RM, Urschel HC, Tripp LE, Levy MF, Husberg BS, et al. Alcohol use following liver transplantation for alcoholic cirrhosis. Transplantation 1996;62(8):1060-3.

61. Gish RG, Lee A, Brooks L, Leung J, Lay JY, Moore DH $2^{\text {nd }}$. Long-term follow-up of patients diagnosed with alcohol dependence or alcohol abuse who were evaluated for liver transplantation. Liver Transpl 2001;7(7):581-7.

62. Goldar-Najafi A, Gordon FD, Lewis WD, Pomfret E, Pomposelli JJ, Jenkins RL, et al. Liver transplantation for alcoholic liver disease with or without hepatitis C. Int J Surg Pathol 2002;10(2):115-22.

63. Grat M, Lewandowski Z, Grat K, Wronka KM, Krasnodebski M, Barski K, et al. Negative outcomes after liver transplantation in patients with alcoholic liver disease beyond the fifth post-transplant year. Clin Transplant 2014;28(10):1112-20. doi: 10.1111/ctr.12427.

64. Hartl J, Scherer MN, Loss M, Schitzbauer A, Farkas S, Baier L, et al. Strong predictors for alcohol recidivism after liver transplantation: non-acceptance of the alcohol problem and abstinence of <3 months. Scand J Gastroenterol 2011;46(10):1257-66. doi: 10.3109/00365521.2011.603160. 
65. Hwang S, Lee SG, Kim KK, Kim KH, Ahn CS, Moon DB, et al. Efficacy of 6-month pretransplant abstinence for patients with alcoholic liver disease undergoing living donor liver transplantation. Transplant Proc 2006;38(9):2937-40.

66. Immordino G, Gelli M, Ferrante R, Ferrari C, Piaggio F, Ghinolfi D, et al. Alcohol abstinence and orthotopic liver transplantation in alcoholic liver cirrhosis. Transplant Proc 2009;41(4):1253-5. doi: 10.1016/j.transproceed.2009.03.092.

67. Jain A, DiMartini A, Kashyap R, Youk A, Rohal S, Fung J. Long-term follow-up after liver transplantation for alcoholic liver disease under tacrolimus. Transplantation 2000;70(9):1335-42.

68. Jauhar S, Talwalkar JA, Schneekloth T, Jowsey S, Wiesner RH, Menon KV. Analysis of factors that predict alcohol relapse following liver transplantation. Liver Transpl 2004;10(3):408-11.

69. Karim Z, Intaraprasong P, Scudamore CH, Erb SR, Soos JG, Cheung E, et al. Predictors of relapse to significant alcohol drinking after liver transplantation. Can J Gastroenterol 2010;24(4):245-50.

70. Kelly M, Chick J, Gribble R, Gleeson M, Holton M, Winstanley J, et al. Predictors of relapse to harmful alcohol after orthotopic liver transplantation. Alcohol Alcohol 2006;41(3):278-83.

71. Koljonen V, Aberg F, Rovasalo A, Mäkisalo H. Self-reported alcohol use and depressive symptoms after liver transplantation. Transplantation 2015;99(4):867-72. doi: 10.1097/TP.0000000000000425.

72. Kollmann D, Rasoul-Rockenschaub S, Steiner I, Freundorfer E, Györi GP, Silberhumer G, et al. Good outcome after liver transplantation for ALD without a 6 months abstinence rule prior to transplantation including post-transplant CDT monitoring for alcohol relapse assessment - a retrospective study. Transpl Int 2016;29(5):559-67. doi: 10.1111/tri.12756.

73. Kumar S, Stauber RE, Gavaler JS, Basista MH, Dindzans VJ, Schade RR, et al. Orthotopic liver transplantation for alcoholic liver disease. Hepatology 1990;11(2):159-64.

74. Lucey MR, Merion RM, Henley KS, Campbell DA Jr, Turcotte JG, Nostrant TT, et al. Selection for and outcome of liver transplantation in alcoholic liver disease. Gastroenterology 1992;102(5):1736-41.

75. Lucey MR, Carr K, Beresford TP, Fisher LR, Shieck V, Brown KA, et al. Alcohol use after liver transplantation in alcoholics: a clinical cohort follow-up study. Hepatology 1997;25(5):1223-7.

76. Mackie J, Groves K, Hoyle A, Garcia C, Garcia R, Gunson B, et al. Orthotopic liver transplantation for alcoholic liver disease: a retrospective analysis of survival, recidivism, and risk factors predisposing to recidivism. Liver Transpl 2001;7(5):418-27.

77. Masson S, Marrow B, Kendrick S, Elsharkawy AM, Latimer S, Hudson M. An 'alcohol contract' has no significant effect on return to drinking after liver transplantation for alcoholic liver disease. Transpl Int 2014;27(5):475-81. doi: 10.1111/tri.12283.

78. Miguet M, Monnet E, Vanlemmens C, Gache P, Messner M, Hruskovsky S, et al. Predictive factors of alcohol relapse after orthotopic liver transplantation for alcoholic liver disease. Gastroenterol Clin Biol 2004;28(10 Pt 1):845-51.

79. Nickels M, Jain A, Sharma R, Orloff M, Tsoulfas G, Kashyap R, et al. Polysubstance abuse in liver transplant patients and its impact on survival outcome. Exp Clin Transplant 2007;5(2):680-5.

80. Osorio RW, Ascher NL, Avery M, Bacchetti P, Roberts JP, Lake JR. Predicting recidivism after orthotopic liver transplantation for alcoholic liver disease. Hepatology 1994;20(1 Pt 1):105-10.

81. Pageaux GP, Bismuth M, Perney P, Costes V, Jaber S, Possoz P, et al. Alcohol relapse after liver transplantation for alcoholic liver disease: does it matter? J Hepatol 2003;38(5):629-34.

82. Park YH, Hwang S, Ahn CS, Kim KH, Moon DB, Ha TY, et al. Living donor liver transplantation for patients with alcoholic liver disease. Korean J Hepatobiliary Pancreat Surg 2013;17(1):14-20. doi: 10.14701/kjhbps.2013.17.1.14.

83. Pereira SP, Howard LM, Muiesan P, Rela M, Heaton N, Williams R, et al. Quality of life after liver transplantation for alcoholic liver disease. Liver Transpl 2000;6(6):762-8. 
84. Perney $P$, Bismuth $M$, Sigaud $H$, Picot $M C$, Jacquet $E$, Puche $P$, et al. Are preoperative patterns of alcohol consumption predictive of relapse after liver transplantation for alcoholic liver disease? Transpl Int 2005;18(11):1292-7.

85. Pfitzmann R, Schwenzer J, Rayes N, Seehofer D, Neuhaus R, Nüssler NC. Long-term survival and predictors of relapse after orthotopic liver transplantation for alcoholic liver disease. Liver Transpl 2007;13(2):197-205.

86. Plat KP, Mueller AR, Spree E, Schumacher G, Nüssler NC, Rayes N, et al. Liver transplantation for alcoholic cirrhosis. Transpl Int 2000;13(1):S127-30.

87. Poynard T, Naveau S, Doffoel M, Boudjema K, Vanlemmens C, Mantion G, et al. Evaluation of efficacy of liver transplantation in alcoholic cirrhosis using matched and simulated controls: 5year survival. Multi-centre group. J Hepatol 1999;30(6):1130-7.

88. Reeck UH, Egerer G, Otto G, Hoffmann W, Arnold JC, Theilmann L, et al. [Rehabilitation of patients with alcoholic liver cirrhosis after orthotopic liver transplantation: a 7-year follow-up]. Rehabilitation 1997;36(2):116-20.

89. Rice JP, Eickhoff J, Agni R, Ghufran A, Brahmbhatt R, Lucey MR. Abusive drinking after liver transplantation is associated with allograft loss and advanced allograft fibrosis. Liver Transpl 2013;19(12):1377-86. doi: 10.1002/It.23762.

90. Rodrigue JR, Hanto DW, Curry MP. Substance abuse treatment and its association with relapse to alcohol use after liver transplantation. Liver Transpl 2013;19(12):1387-95.

91. Rodrigue JR, Hanto DW, Curry MP. The Alcohol Relapse Risk Assessment: a scoring system to predict the risk of relapse to any alcohol use after liver transplant. Prog Transplant 2013;23(4):310-8. doi: 10.7182/pit2013604.

92. Schmeding M, Heidenhain C, Neuhaus R, Neuhaus P, Neumann UP. Liver transplantation for alcohol-related cirrhosis: a single centre long-term clinical and histological follow-up. Dig Dis Sci 2011;56(1):236-43. doi: 10.1007/s10620-010-1281-7.

93. Shakil AO, Pinna A, Demetris J, Lee RG, Fung JJ, Rakela J. Survival and quality of life after liver transplantation for acute alcoholic hepatitis. Liver Transpl Surg 1997;3(3):240-4.

94. Stilley CS, DiMartini AF, de Vera ME, Flynn WB, King J, Sereika S, et al. Individual and environmental correlates and predictors of early adherence and outcomes after liver transplantation. Prog Transplant 2010;20(1):58-66; quiz 67.

95. Tang H, Boulton R, Gunson B, Hubscher S, Neuberger J. Patterns of alcohol consumption after liver transplantation. Gut 1998;43(1):140-5.

96. Tomé S, Martinez-Rey C, Gonzalez-Quintela A, Gude F, Brage A, Otero E, et al. Influence of superimposed alcoholic hepatitis on the outcome of liver transplantation for end-stage alcoholic liver disease. J Hepatol 2002;36(6):793-8.

97. Tringali RA, Trzepacz PT, DiMartini A, Dew MA. Assessment and follow-up of alcohol-dependent liver transplantation patients. A clinical cohort. Gen Hosp Psychiatry 1996;18(6 Suppl):70S-77S.

98. Van Thiel DH, Bonet $\mathrm{H}$, Gavaler J, Wright HI. Effect of alcohol use on allograft rejection rates after liver transplantation for alcoholic liver disease. Alcohol Clin Exp Res 1995;19(5):1151-5.

99. Walter M, Scholler G, Moyzes D, Hildebrandt M, Neuhaus R, Danzer G, et al.. Psychosocial prediction of abstinence from ethanol in alcoholic recipients following liver transplantation. Transplant Proc 2002;34(4):1239-41.

100. Wiesner RH, Lombardero M, Lake JR, Everhart J, Detre KM. Liver transplantation for end-stage alcoholic liver disease: an assessment of outcomes. Liver Transpl Surg 1997;3(3):231-9.

101. Zelle DM, Agarwal PK, Ramirez JL, van der Heide JJ, Corpeleijn E, Gans RO, et al. Alcohol consumption, new onset of diabetes after transplantation, and all-cause mortality in renal transplant recipients. Transplantation 2011;92(2):203-9. doi: 10.1097/TP.0b013e318222ca10. 
102. Zhou M, Wagner LM, Diflo T, Naegle M. Implementation of the High-Risk Alcoholism Relapse Scale in a Liver Transplant Clinic. Gastroenterol Nurs 2015;38(6):447-54. doi: 10.1097/SGA.0000000000000168.

103. Dobbels F, Vanhaecke J, Nevens F, Dupont L, Verleden G, Van Hees D, et al. Liver versus cardiothoracic transplant candidates and their pretransplant psychosocial and behavioral risk profiles: good neighbors or complete strangers? Transpl Int 2007;20(12):1020-30.

104. Allen JP, Wurst FM, Thon N, Litten RZ. Assessing the drinking status of liver transplant patients with alcoholic liver disease. Liver Transpl 2013;19(4):369-76. doi: 10.1002/It.23596.

105. Telles-Correia D, Barbosa A, Mega I, Direitinho M, Morbey A, Monteiro E. Psychiatric differences between liver transplant candidates with familial amyloid polyneuropathy and those with alcoholic liver disease. Prog Transplant 2008;18(2):134-9.

106. Obed A, Stern S, Jarrad A, Lorf T. Six month abstinence rule for liver transplantation in severe alcoholic liver disease patients. world J Gastroenterol 2015;21(14):4423-6. doi: 10.3748/wjg.v21.i14.4423.

107. O'Donnell A, Anderson P, Newbury-Birch D, Schulte B, Schmidt C, Reimer J, et al. The impact of brief alcohol interventions in primary healthcare: a systematic review of reviews. Alcohol Alcohol 2014;49(1):66-78. doi: 10.1093/alcalc/agt170.

108. Heikkila K, Nyberg ST, Fransson El, Alfredsson L, De Bacquer D, Bjorner JB, et al. Job strain and alcohol intake: a collaborative meta-analysis of individual-participant data from 140,000 men and women. PLoS One 2012;7(7):6. doi: 10.1371/journal.pone.0040101. 


\section{FIGURES AND TABLES LEGEND}

Figure 1: $\quad$ Overview of included studies

Figure 2: $\quad$ Quality assessment

Table 1: $\quad$ Search string programmed in PubMed

Table 2: $\quad$ Pooled odds ratios for correlates and outcomes of any alcohol use and at-risk drinking

Table 3: $\quad$ Correlates of any alcohol use and at-risk drinking investigated $<5$ times 